\title{
COMMUNICATION - THE FOUNDATION FOR EVERYTHING
}

\section{Ms. Nirupama Patel}

\begin{abstract}
Good verbal communication skills are crucial not only for the students' learning while at university, but also for their future as professionals in almost any career path they will pursue. Communication is considered as one of the University's generic graduate attributes. The IT revolution and globalization of business have brought technical communication to the forefront of academia and industry. Experts and technocrats have to face new encounters in communications as the whole world becoming the global market and businesses becoming diverse and result -oriented.
\end{abstract}

Keywords: Communication; Professional; Career; Globalization.

\section{Why communication?}

Success in this competitive world depends not only in getting knowledge and hard skills, but also on developing effective technical communication skills. It is a fact that having knowledge is not sufficient until and unless you express it orally. The problems which now occur in front of the student is that exercising only on non- verbal and the aspects of personality development is not enough, they have to work on English both in the written and oral form. Having a command on English i.e. communication skills plays a vital role and act as an icing of the cake and brings an attitude into oneself. So the main issue faced by the students is how to communicate effectively in English and what efforts to be made to cope up with this problem.

Inspiring students in teaching procedure is an essential part of current education. This is deep-rooted by many means. First of all, child-centred tactic to education, which emphases on child and its requirements, needs, feelings, interests etc. Secondly, several studies have revealed that education is more active when an expressive factor is involved (feeling of safety, admiration, inquisitiveness, happiness etc). Thirdly, school has missed the competition with life that is going on in external world. Students consider school as a tedious place where students go because it is compulsory for them. So as to play its ethnic, developing and socialization role, school must have to find out 
how to provide a serving hand to students, i.e. it has to search for the policies for attracting students.

Though, good attitude and pleasing atmosphere in a classroom should not be mixed up with creative break, stress-free pastime or lively talk room - as often seen by laymen. The teacher should pass onto students' valuable information and skills. What is even more significant than the verbal message is the message that is conveyed to students through experience they have in a well-controlled and organised class. Good communication skills are of very important in that sense.

The chief source of inspiration is an expressive and interesting class, i.e. cautiously planned task in which the students can actively join and there is worth informative communication. Expressive means that the objective of the activities is clear to all the students and that the objective is significant, beneficial and satisfactory for them. For e.g. a topic should be correlated to the students' benefits, present-day events or motivating examples from day to day life, taking into account the prevailing information and experience of students. This will ensure that the lesson is motivating, noticeable, amusing and carefully selected or made materials are also important.

Good method for increasing student inspiration and attention is direct and active participation in class activities. It is very necessary that all the students should be involved in all the activities. The exercise content and the material should be related to the subject content wherever possible. So it is advisable to point out and demonstrate to the students how the particular exercise can be useful for knowledge, remembering, reproducing earlier learned. This is a significant cause of inspiration. The teacher should also, when considered suitable, deliver the idea of the significance of critical thinking, with the description that the modern world in all its forms is the world of computers and critical thinking. It is irrespective of what the students plan to do in the future, they cannot find their way in the chaos of facts, substitutions and managements without critical thinking.

\subsection{Certain Communication Techniques}

- Group work increases inspiration. For this the tasks should be well organized and developed and the expected outcomes should be well-defined in advance. The tasks should be designed in a stimulating way so as to draw students' attention and motivate them. Step-by-step introduction of the lesson topic with clearly defined lesson structure is advisable.

What the working groups or classes did should be used in teaching in the future and also useful to other students to take ideas.

When the activities are done in groups, competitive atmosphere is there and that is highly motivating. 
Towards Excellence: An Indexed, Refereed \& Peer Reviewed Journal of Higher Education_ Ms.

Nirupama Patel / Page 190-195

If debate or group discussion is there in the class, different approaches, views and different methodologies can be learnt.

It is good if students are asked in which way they would like a certain topic to be taught within the class and discuss accordingly.

$>$ Topic can become more dynamic if group work is combined with individual work. Each student in the group should have a specific task.

The teacher should confirm that the role of student in the teaching process is wide-ranging. Exchanging roles empowers students to take different positions in different situations and to learn which situations and roles suit them the best. On the other hand, psychological tension which every unknown situation brings along is a good means of motivation.

Feedback on the quality of work and the class in general should be frequently given- after each phase of the lesson. For e.g.: "This was outstanding, keep it up" etc.

In certain phases of class the students should be given small specific tasks which make students focus on the topic or situation, that enable them to get info about the quality of their work directly.

\section{Importance of Communication}

All teamwork begins with a common footing. The foundation is created by communication. Without knowledge about your own communication, it is impossible to analyse others' communication, and thereby it will be difficult to be diplomatic and build channels between different opinions. If you are a good communicator you can discuss problems with other people instead of arguing with them.

The most eccentric by communication is that we can't stop doing it. We are always communicating, even when we are not talking to each other or looking at each other. In such situation we will often communicate that we don't want to talk with others. Think about a trip in a train, sitting opposite unknown people, or standing in the line in a supermarket.

\subsection{Things that Influences Conversation}

The model underneath is developed to explain what happens when we communicate and what influences discussion.

Context is the connection that the communication is a part of. It can be a conversation about abilities or a conversation between a supervisor and an operator. 
The code is the language. It can be English, Danish or Arabic, but it can also be technical language or slang.

The message is what you want to tell. In this situation you can talk about direct or indirect messages. The indirect is the message you can read or hear "amongst the lines" and often these messages are more significant than the direct communications.

The channel is the way you convey the message. It can be by the language, body language, or touch for e.g. what can make communication difficult is that we, as communicators, use a lot of personally filters. We use these filters to choose what we want to say and to understand.

The filters that we understand through, and choose what and how we want to communicate, are closely linked to our contextual and our personality. They can include of our experience with: the person, similar situations, our needs to proclaim ourselves or our fear to be too high and enormous, our upbringing and our education.

\subsection{Development of Communication Skills}

A review of literature indicates that oral communication has been identified as a learnable skill and that experiential methods have generally yielded better results than purely didactic means [1].

\section{Presentations}

\section{Group presentations}

Group presentation creates in students the quality to work in a group. Many of the students who are not so open in front of others also take part actively in group and share their thoughts. Leadership quality also develops in students as in a team, two-three students are very active and take the responsibility of the work assigned in group. Other students also get motivation from them. They work together to fulfil one common goal. This will be very helpful when they do job.

\section{Peer Review}

Benefits of peer assessment include getting students to think about the exercise more intensely, distinguish others' perspectives and how to give positive criticism to peers. Disadvantages include probable prejudice, reluctance to give low marks for poor work from their peers and the need for clearer guidelines, although these can be contradicted by utilising group-based marking, rather than individual, increasing marking guideline specificity, and limiting the impact of the peer review exercise on the overall unit grade.

\section{Role-Play}


As knowledge of communication theory does not essentially similar skills in practice, it is important to engage students in similar work environments. Context-specific representations, or role-play, can focus the student's attention on the differing types of communication required with various groups in prospective future work situations.

\section{Video}

Video/audio grading has been shown to intensely improve presentation skills in students, with one prime example given where student presentations were filmed and then graded with dubbing from the teacher and a feedback sheet [1]. Importantly, this provides appropriate educational feedback to the student that is not transitory as the student's performance can be reassessed.

\section{Technology}

Modern technology should be utilised, or at least demonstrated to the students, so that they are aware of what is in use beyond the university walls. The Irish study found that practising engineering graduates suggested that greater content for communication courses in undergraduate engineering cover basic MS Office applications (number 3 on the list, directly after oral presentations and keyboard skills), as well as other technical elements including Web page design, e-mail and graphic design [2]. This gives a clear indication of technological fundamentals that need to be combined into fundamental communication training for engineering students in preparation for industry.

\section{Active Involvement of the Learner}

Littlewood suggested several elements that involve the learner to reinforce learning:

- The classroom must be conducive to communication and learning;

- Learning has to be relevant to learners' interests and needs;

- Processes and products are important in the classroom;

- Learners must engage in active roles in the classroom [3].

\section{Team-Teaching Collaborations}

Team-teaching collaboration between a subject expert and an English language teacher can help learners. Overseas experience already indicates that the interaction from team-teaching can suggestively improve the written and communication skills of most the students, particularly oral presentations and report writing.

\section{Assessment of communication skills}

Communication skills have been known as multidimensional and so it becomes vital to categorize how they will be evaluated in the students' work. Additionally, the specific communication skills required in a career are usually ill defined. One study identified that communication skills assessment must:

- Be formal so that it occurs at specific times and contributes to a student's marks;

- Provide feedback to be educational; 
- Involve active participation by students in actual communication situations;

- Tackle student insights so that skills are identified and developed [4].

Individual feedback is important but there needs to be prudent identification and clear operational definitions of the rating dimensions so that the same standards are applied to all students: consistency and accuracy [4].

\section{Conclusion}

Language and communication skills are known as significant features in the education of the modern engineer. The institutions that have already applied multilingual and communication elements will be at the front position of providing the requirements of industry and society. The overcrowded engineering curriculum still needs to incorporate further proficiencies, notably place of work and world-wide intercultural skills, especially communication. Fitting in a new subject will, in most cases, be difficult, but also less persistent with regard to the competence being taught. The assimilation of communication skills, as can be found in various business prospectuses, will serve to reinforce such skills like communication across different contexts, particularly if students recognise this as an important component if part of the overall grade is attributed to it.

\section{References}

[1] Polack-Wahl, J.A., 2000. It is time to stand up and communicate. Proc. 30th ASEE/IEEE Frontiers in Educ. Conf., Kansas City, USA, F1G-16-F1G-21.

[2] Keane, A. and Gibson, I.S., 1999. Communication trends in engineering firms: implications for undergraduate engineering courses. Inter. J. of Engng. Educ., 15, 2, p.115-121.

[3] Littlewood, W., 1992. Teaching Oral Communication: a Methodological Framework. Oxford: Blackwell.

[4] Jones, K.V., 1996. Assessment of communication skills: ratings of videotaped behaviour samples. Proc.Australian Communication Conf., Melbourne, Australia, p. 67-74.

\section{Ms. Nirupama Patel}

Assistant Professor

Gandhinagar Institute of Technology, Gandhinagar 